\section{Multidisciplinary SCIENTIFIC JOURNAL OF MARITIME RESEARCH}

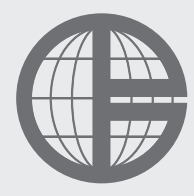

University of Rijeka

Faculty of Maritime

Studies Rijeka
Multidisciplinarni

znanstveni časopis

POMORSTVO

\title{
Discourse exponents of standing orders on board ship
}

\author{
Milena Dževerdanović-Pejović \\ University of Montenegro, Maritime Faculty, Dobrota 34, 85330 Kotor, Montenegro, e-mail: milenadz@ac.me
}

\begin{abstract}
Deck officers must be very familiar with the content of the Standing Orders. This peculiar genre, which is usually written on one page of text and with a distinguishable graphical layout, combines administrative and legal discourse. The subtle interrelation between linguistic features on different levels of the analysis implies the ship's hierarchy and organization which is a precondition for the safety of the ship. Analysis in this paper relies on discourse and genre knowledge and represents a continuation of the author's research on maritime written genres in terms of both their structure an interpretation of language facts.

Structure analysis in the paper is based on Bhatia's (1993) model. After the moves of Standing Orders were established, the analysis focused on discursive characteristics of each move. As Standing Orders as genre for the most part belong to legal discourse (apart from commercial and merchant discourse), the analysis tends to show correlation between discourse exponents of this legal genre and crew members' position and duties on board ship.

Findings of this paper can be pedagogically useful in terms of providing a teaching model that will aid Maritime English teachers to convey knowledge of this genre to students, especially future deck officers and ship masters.
\end{abstract}

\section{ARTICLE INFO}

Review article

Received 9 November 2015

Accepted 9 June 2016

\section{Key words:}

Standing Orders

Legal discourse

Genre analysis

Discourse analysis

\section{Introduction}

Standing Orders represent a written document containing the ship Master's advice and instructions on how to operate the ship. They are posted in a visible place on board and serve as a reference on what actions to take or not to take on board. Standing Orders are one of the regulative tools used to control the performance of operating procedures on board ship, in line with the language competence for operational level laid down by the International Convention on Standards of Training, Certification and Watchkeeping 1978 as amended in 1995 and 2010. For example, regarding navigation the operational level, watchkeeping at sea, "|relieving officers shall personally satisfy themselves regarding the standing orders and other special instructions of the master relating to navigation of the ship"| (STCW, 2010: 225).

While it is not unusual to find many rulebooks on board ships, the peculiarity of the Master's Standing Orders as a document lies in the fact that it incorporates the Master's personal expectations and habits in between the lines of text. It reflects a kind of 'tacit' agreement that has been signed between the Master and the officers about the future routine of life on board. Although Standing Orders documents may appear as a uniform text used by ship Masters to lay down the rules of professional command on board, their content is more personalized. What is more, Standing Orders create a kind of trust between the Master and the officers. "The officers will know when the Master wants to be called and the Master will know that they will so" (Beetham, 2000: 229).

In terms of previous research into this peculiar genre, the author is not familiar with any efforts towards Standing Orders analysis in the light of the discourse analysis approach. A master thesis that is relevant to the issues tackled in this paper examines Standing Orders as a genre from the angle of contemporary genre theory (Turner 2006). Through interviews with ships' Masters and crew and the diachronic analysis of Standing Orders, the author explains the notion of genre and power in a maritime context, that is, the relationship between the subordinate and subordinated member in a maritime context. Turner (2006: 25) sees the following relations between Standing Orders and the notion of power.

"In imposing obligations and establishing relationships, Standing Orders define power in two ways.

First, they provide a means for the commanding of- 
ficer to reserve power. In other words, they allow the commanding officer to keep decision-making authority. Second, they delegate power to subordinate watch standers by giving them leave to make decisions".

In view of the above, the present study aims to broaden knowledge about Standing Orders as a genre in order to offer one solution of teaching Standing Orders based on genre analysis theory. Besides, establishing structure and establishing its discursive features can be exploited by deck officers and masters, directly involved in writing this document on board ship. Finally, investigating legal language used in Standing Orders as a genre helps to reveal interrelation between language and maritime setting, i.e. to indicate how language reflects hierarchy on board ship.

\section{Genre analysis approach}

The genre knowledge and genre analysis approach taken here heavily relies on the examination of the concept of genre provided by Swales (1990) and Bhatia (1993). Genre is seen as a dynamic and changeable category whose patterning is the reflection of social changes. Talking about genre in a specialized or professional discourse community implies knowing the conventions of the genre of that community (Bhatia, 1993: 15).

However, a genre analysis decoding means more than focusing on the form and function relationships, as it goes beyond the material substance present in the text. "There is usually a close link between the type of specialized text and it structure, which in turn implies a number of correlations between the conceptual, rhetorical and linguistic features that characterize the text itself" (Gotti, 2008: 112).

There is no doubt that the concept of genre has passed a long way towards becoming a fact of language and not literature, a "sociologic fact, a matter of social etiquette, or something like the natural organism" (Frow, 2006: 52). In this light, the effort made here is to analyze one peculiar genre in a very specific setting, where the authority of one person directly influences the whole team. The genre under scrutiny was seen by the author as a legal genre, bearing in mind its highly codified structure, statutory clauses, authoritative argumentation and rhetoric.

\section{Method}

For the purpose of this study, 30 Standing Orders were examined. The average length of the Standing Order document is from one to four A4 format pages. The corpus includes collection of Standing Orders from different companies collected in the period from 1980 to 2014. The names of the ships and captains have been changed.

After the texts were carefully read, it was easy to establish the three move model based on theory set forward by Bhatia (1993). Then, the focus was shifted to the microlevel and description of syntactic and lexical features pertaining to each move.
In order to identify specific lexical features in Standing Orders, the programme WordSmith ${ }^{1}$ tools was used. One among many benefits of this software is that it was possible to count occurrence of the chosen word and its collocation with other lexemes. In this paper, it was used to calculate occurrence of lexical pairs (binomials) and frequent grammar structures such as shall + infinitive indicating obligation in institutional documents.

\section{Findings}

As regards the structure, and relying on the move structure model (Bhatia 1993), the following moves can be identified in the Standing Order as a genre:

\section{MOVE 1 Conventional Introduction \\ MOVE 2 Enumeration \\ MOVE 3 Standardized Ending}

\subsection{Move 1 - Conventional Introduction}

As regards the graphical layout of the introductory part of the Standing Order document, it resembles a decree or charter. The text which is inserted in the box is highlighted by capital letters. No doubt the text catches the reader's attention at first sight and reading. This kind of introductory segment is found in five examples of Standing Order texts. It is introduced by the heading Paramount Clause, a phrase present in the legal discourse implying the most important rule or principle. Examples of this phrase is also to be found in commercial discourse or merchant maritime discourse found in the oldest shipping documents such as the Charter Party and Bill of Lading.

(1) PARAMOUNT CLAUSE -

THE SAFETY OF THE SHIP AND ITS PERSONNEL IS ALWAYS TO BE THE PRIME CONSIDERATION, TAKING PRECEDENCE OVER ANY OTHER. NO CONSIDERATION OF PROGRAMME, CONVENIENCE OR PREVIOUS INSTRUCTIONS JUSTIFIES TAKING ANY RISK, WHICH MAY PLACE THE SHIP IN DANGER.

The presence of the legal discourse initiated in the above graphical example is further visible at the level of syntax. The presence of the discourse of legislative provisions is seen in the length of the sentences. The average number of words in the two sentences in the first example is 20 words. The nominal characteristics of the text, which are indicative of legal discourse according to Bhatia (1993: 107), are also present in the object phrase prime consideration following after is/are + to be. What follows are the nouns consideration and precedence and the trinomial programme, convenience or previous instructions. Another example of a decree-like introduction, with similar content and phrases is as follows:

\footnotetext{
Scott, M. (2011) Text Analysis Software Wordsmith Tools 5.0, http:// lexically.net/wordsmith/downloads/
} 
(2) PARAMOUNT CLAUSE -

THE SECURITY OF SHIP AND ITS PERSONNEL SHALL BE TAKEN SERIOUSLY, IT IS THE AIM OF THE SHIP AND ITS PERSONNEL TO PROVIDE SECURE OPERATIONS, TO PROTECT US AND ANY THIRD PARTY FROM RISK OF INJURY, LOSS OR DAMAGE, FROM CRIMINAL, HOSTILE OR MALICIOUS ACT.

The whole section consists of a single sentence numbering 47 words. Binomial and trinomial expressions, which are prominent features of legislative texts, are also present so that the binomial ship and its personnel is present twice, as well as the binomial loss or damage and the trinomial criminal, hostile or malicious. Binomial and trinomial expressions found in legislative texts in which two or more interchangeable terms are used for the same concept are effective linguistic device adding all-inclusiveness and preciseness to the text (Bhatia 1993: 108). It is arguable though, knowing that Standing Orders should be clear and unambiguous to all officers, whether the use of these redundant structures serves its purpose. In a maritime setting the answer is yes, as the written discourse took over the characteristics of oral communication in which repletion and redundancy are crucial for the proper interpretation of information.

The use of shall + infinitive in the second example is used to express obligation as in "The Security of ship and its personnel shall be taken seriously". Finally, as regards semantic aspects, one discourse exponent of court discourse is present in the form of the phrase third party.

As regards Move I - Conventional Introduction in other examples of Standing Orders, it is found that they do not contain the introductory Paramount clause. The recent introductions to Standing Orders documents, going back over a five years period, do not feature this kind of introduction or any aesthetical or graphical components. Rather the authors (Masters) apply a familiar tone and use an in media res introduction stating the purpose of the Standing Order. This kind of introduction is present in 20 examples.

(3) The purpose of this procedure is to set rules of behaviour on board $\mathrm{m} / \mathrm{v}$ Harmonia in accordance with the Code of Conduct of USA Merchant Navy.

(4) The Officer of watch shall be guided by the contents of International Regulation and Guidelines, but paying particular attention to the following.

Another five examples in the corpus do not have a conventional introduction and the Master directly starts with in medias res narrative, or Move 2, listing his orders or recommendations.

\subsection{Move 2 - Enumeration}

The longest narrative part of the Standing Order is at the same time the core of the Standing Order document. In a graphical sense, the Master's recommendations and instructions are neatly enumerated and highlighted either by bullet points or numbers, or sometimes by letters of the alphabet. Often, the Master applies capital letters, italics or other graphical solutions to emphasize the orders which are of higher priority. In some of these examples of Standing Orders, the Master often classifies orders under an appropriate heading or theme like Navigation Bridge, Radar, In Port, At Sea or Watch Standing.

In the following Enumeration move, present in five texts of Standing Orders, the analysis of the Enumeration part is mainly based on cognitive structuring model of legal provisions text analysis set forward by Bhatia (1993). These are the texts of an older date, mainly those with the "paramount clause" introductions. The legal and solemn tone from the Introduction move is continued into the Enumeration part. This language tool therefore belongs to older generations of Masters, who preferred an archaic and legal style in writing.

According to Bhatia (1993: 116) the legislative genre consists of the main provisionary clause and additional qualifications or qualification insertions. This model enables us to identify the structural organization of the genre and to grasp the interplay between the two parts.

The following segments from the Standing Orders are broken down according to Bhatia's model mentioned above (1993):

\section{Provisionary clause}

All OOW are to

familiarize themselves with the section on tropical storms and shall

notify the Master about any fall of barometric pressure of $3 \mathrm{mb}$ or more in any period of less than four hours

\section{Qualifications}

for the sake of becoming conversant with all prescribed safety regulations carrying out duties of OOW,

in case any of the precursory signs of a tropical depression for the purpose of timely and immediate reaction.
The main pragmatic purpose of such a discourse is to make the statement clear and unambiguous. The qualifications in this text serve to clarify the main provisions and answer any doubts that the reader (in this text the deck officers) might have. The Master in the above sentences expresses the order using the structure is/are to + verb infinitive as in "OOW are to familiarize", and the modal shall for obligation as in "shall notify". The additional elements given in the qualifications are explanatory and mitigate the effect of the strong order given in the provisionary clause.

This legal discourse is, as mentioned in the above text, used in the older documents starting with the Paramount Clause introduction. However, in other examples of the Standing Orders, those orders are listed and in some cases numbered. In some examples letters of the alphabet or bullet points are used to separate orders.

\subsubsection{Expressing obligations in Move 2 - Enumeration}

As mentioned in the previous text, the structure is/are to+infinitive $(5,6,7)$ is very widely applied (30 examples) 
but the passive form is/are to + passive infinitive is also present in the Enumeration part in 68 examples. With the "active structure", the subject in the sentence is usually the person who is supposed to be active, whether it refers to lookouts, deck officers, officers of the watch, able-bodied seamen or ordinary seaman. On the other hand, in examples with the passive infinitive, the subject of the passive sentences is usually an activity or practice to which the order refers, such as navigation (8) or activities on board that have to be properly performed, reported or confirmed (9-12).

(5) Officers are to read company regulations and carry out the duties prescribed therein.

(6) All oow are to become proficient in all steering systems including buttons to de-assign thrusters, shifting between hand steering and Autopilot.

(7) The AB or OS is to be posted as lookout in all cases of reduced visibility.

(8) The CPA (closest point of approach) and relative motion of these targets are to be monitored closely by the watch.

(9) Any damage to ship, ship's equipment or cargo, caused by stevedores, is to be drawn immediately to the attention of the Gang Foreman or Supervisor.

(10) A stowaway search is to be carried out prior to departure.

(11) Every order or information given from the Bridge is to be confirmed by repeating.

(12) Any hot work outside the workshop to be reported.

The necessity to comply with the regulations laid down by the Master and to react without delay in case they are breached is contained in the most frequent adverb in the corpus - immediately. It implies that there is no time to wait when any activities on board "deviate from" routine practice.

The verbs accompanying the adverb immediately in the sentence are advise, alert, inform, notify, draw (attention), advise, report and contact. Further examples expressing immediate action on board are expressed by the structure shall + infinitive, which occurs in 120 sentences. It is noticed that the shall + infinitive construction is used in the corpus in those situations in which the Master indicates that the legal provisions are imposed from the outside, i.e., either by a convention or the company's own rules or manual $(13,14,15,16)$, that is, a legal act was not imposed by the Master. Here, the Ship's Master is a kind of intermediary between the company and the crew.

(13) He shall give due regard to Company's rules and Master's Standing Orders and Night Orders.

(14) In conjunction with his Navigational duties, the Watchkeeping Officer shall exercise constant watch keeping vigilance.

(15) The Watchkeeper shall inform the Master in the event of impending adverse weather conditions which would affect the navigation of the vessel.

(16) The Bridge watch shall be at all times adequate and appropriate to the prevailing circumstances and conditions.

The phrase due regard (sent. 13) in a maritime context means that the seafarer will behave in the best possible manner. This legal phrase is very much employed in the contemporary written language of seafaring emphasizing that seafarers have to safeguard the ship as a "good host".

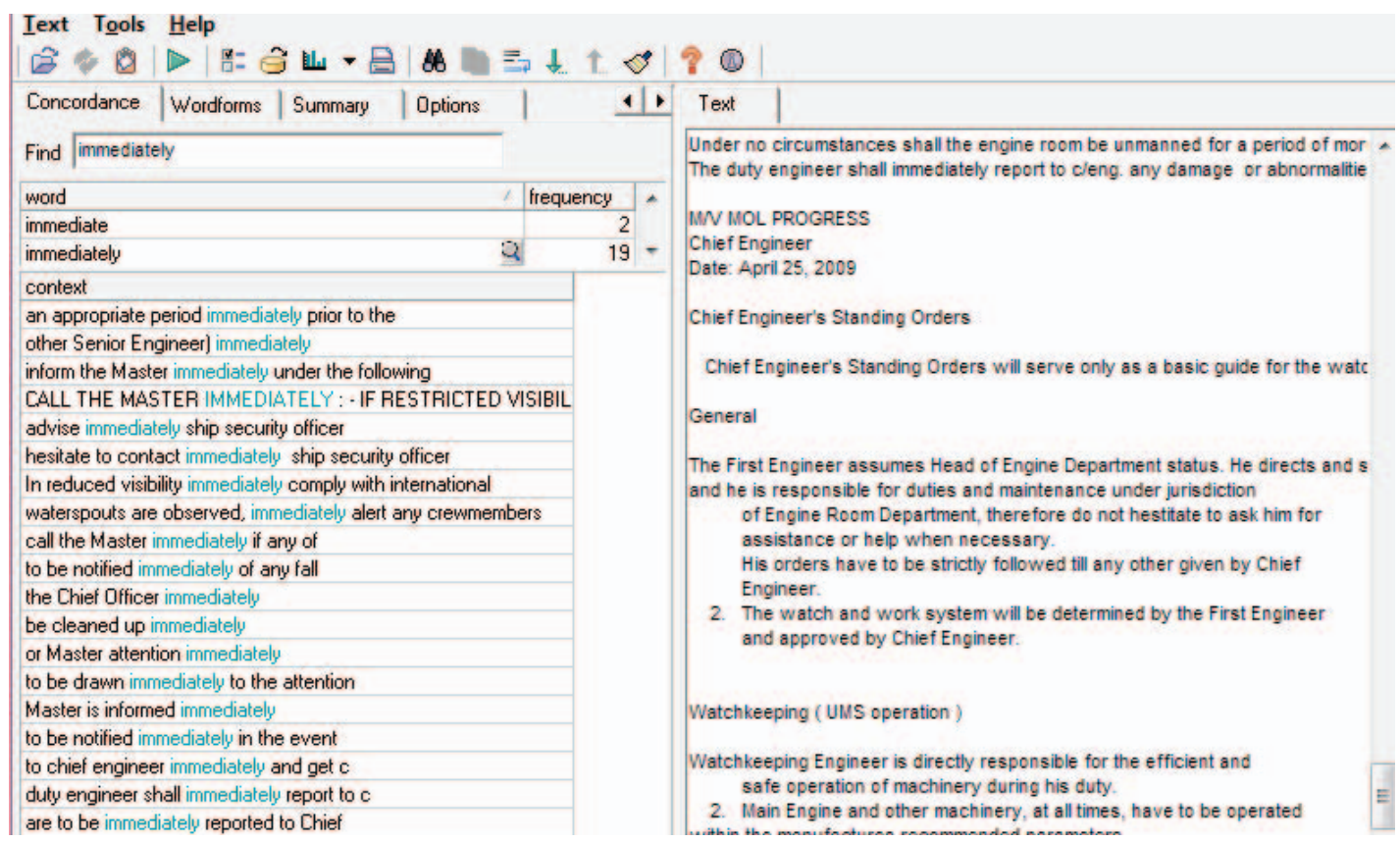

Figure 1 Printscreen of the use of the adverb immediately in the Standing Orders in the Wordsmith tools 5.0 programme 


\subsubsection{Direct orders - The use of the imperative}

The pragmatic purpose of Standing Orders is to make tacit knowledge explicit (Turner, 2006: 31). Thus, in the Enumeration part or Move 2, the Masters use the imperative more than they use impartial address. The imperative is present in 233 sentences in the Standing Orders document.

(17) Make a regular check to ensure that helmsman or automatic pilot is steering the courses.

(18) Let me know in plenty time what you intended to do.

(19) Keep at last three miles off passing is possible and use VHF to exchange necessary information to avoid collision situation.

In addition, the master uses the personal objective pronoun me in 34 examples. Thus, the previous "call the Master if in any doubt" cliché has become "call me if in doubt". Changes in social relationships on board ships have thus been reflected in the language of the plan. This displays the recent trend on the part of Ship Masters' towards positive, rapport-building practices.

The most distinguishable language feature of expressing direct orders in the Standing Order discourse is the use of modal verbs. Of the 92 examples, the modal must occurs 46 times. Their further distribution in descending order is as follows: have to (32), should (13), may (8), can (5). The modals could and might do not appear in the analysed corpus.

Knowing that the main communicative function of the Standing Orders is to oblige officers to respect the rules and activities elaborated in the text of Standing Orders, the obligation is in most cases expresses using the modal must.

(20) His orders must be strictly obeyed.

(21) One deck rating must be continuously alert.

(22) Echo-Sounder must be checked regularly.

(23) His orders must be strictly followed till any other given by Chief Engineer.

The modals may and can are used in those situations when the Master refers to the methods of dealing with equipment, a device or cargo or any navigation rule:

(24) Anchorages can become untenable.

(25) If stand-by generators do not come on load, the breaker of the running generator can be operated manually.

For this purpose, the modal may is also exploited. Thus, the Master explains the manoeuvrability of the ship and the manner of steering $(26,27)$ or the watch keeping routine (28).

(26) In favourable conditions the ship may be steered by automatic pilot but manual steering must be carried out in the following circumstances.

(27) UMS Operation may be changed by Chief Engineer order to normal sea watch at any time.
(28) The O0W may visit chartroom for short periods of time to carry out necessary navigational duties.

\subsubsection{Expressing prohibitions}

The purpose of the Standing Order as a genre, from its very establishment, is to make clear the distinction between allowed and prohibited acts on board. In this light, the Master must choose clear language in laying down these actions. As regards the maritime discourse community, the most common way of expressing forbidden activities on board ship is by (a) the imperative and (b) the use of "negative constructions".

a. One among the many linguistic recommendations refers to the use of negation in Maritime English. For example, as stated in the Introduction to the Standard Marine Communication Phrases (2001: 4) and speaking of verbal communication, only full forms are to be used. Thus it is recommended that people use cannot and must not instead of can't and mustn't. Analogously, the imperative forms used in our corpus contain the negative imperative do not:

(29) If you are authorized to enter in any space, do not leave the access door open when you find it closed.

(30) Do not use VHF except for reporting to VTIS, Port controls and Pilots, especially do not try to avoid collision by calling ships on your starboard side, remember it is your duty to avoid them and do so.

(31) Do not allow look-out A/B to check radars, which is for OOW, and for A/B is visual lookout.

(32) Tug line to be slowly lowered by controlling messenger rope on the bitts - do not just let it go - it can injure tug's crew if they are below.

b. Compared to the instructions or clarifications expressed in the above sentences, the following prohibitions are formed by use of the negative determiners any and no. The so-called negative formulations formed with the determiner any in the subject noun phrase are found in 38 examples. More "obligatory" is the determiner no which is found in 50 examples. Therefore, the illocutionary force varies from that of warning in sentences with any $(33,34)$ to strong prohibition expressed with no (35-37).

(33) Any abnormalities noticed to be reported to First Engineer or Chief Engineer.

(34) Any mistakes are to be crossed with line, corrected and confirmed by signature of responsible person.

The negative determiner no is found in the initial position as the subject in those sentences which presents the Master's emphasis on the content which follows. As regards its communicative function, the prohibitions expressed with no in the initial position belong to action rules, as Gunnarsson (2009) named them. Actions rules are meant either to give the right to do something or, in the case of a breach of law, to lay down a specific penalty to be applied in such situations. 
Therefore, one of the common tacit rules on board states that, because of the omnipresent problems of stowaways on board, officers should not allow any vendor or unauthorised person to get on board (35). In addition, officers of the deck or any crew member should not go on shore without obtaining permission from the first officer or the ship's captain (36). Furthermore, a tacit rule which is explicitly set is that the ship's log is the particular responsibility of the ship's Master and data should not be entered by other people on board, without the permission of the Master or the deck officer (37).

The prohibitions above are intensified by the connectors without $(35,36)$, until $(37)$, except for (38), under no circumstances (39), and neither nor as a negative construction (40). Legislative discourse is visible at the syntactic level is the syntactic discontinuity (38), where the inserted sentences are conditional or compound noun phrases (Bhatia, 1993: 112).

(35) No vendors can be accepted on board without permission of ship security officer.

(36) No deck officer or crew member is to go ashore without first informing the first officer or, in his absence, the Master.

(37) No log book entries concerning the delay are to be made until the Master or Chief Officer is consulted.

(38) Except for the Master and Chief Officer, if for any reason the Master is unable to carry out this engagement, no person can issue abandon ship order.

(39) Under no circumstances shall the engine room be unmanned for a period of more than 8 hours.

(40) Neither the neglect to maintain Engine room nor the bad performance will be tolerated.

As far as prohibitions in the text of the Standing Order as a genre are concerned, it may be assumed that their content has not drastically changed over the years. Applying Gunnarsson's view (2009: 104) it may be said that the legislative content of the Standing Order may be defined as preservation, that is, it is meant to keep certain already approved ways of behaviour from changing. Legislation is thus a means of the confirmation or codification of these existing norms.

\subsubsection{Connectors}

In writing Standing Orders, Ship's Masters tend to justify specific claims and prohibitions pertaining to the professional behaviour of seafarers. Common prepositional phrases include the structure preposition + noun + preposition (Bhatia, 1993: 107) and the connectives expressing intention are in order to and so as to. They are followed by verbs belonging to the semantic field of "prevention" or "control" such as the verbs keep, check, prevent, stop, avoid, and call.

(41) Pump out the water into the Bilge Water Tank in order to keep tank top and bilges clean.
(42) In order to avoid potential hazard to navigation and if traffic conditions are causing concern, officer of the watch should call the master immediately.

(43) Before taking over the watch Engineer has to take routine round so as to check the state of machinery.

(44) Operate the breaker manually so as to stop idling.

(45) All drained oil has to be removed from the drums so as to prevent tainting.

\subsubsection{Nominalization}

Examples of legislative discourse in the Standing Orders as a genre are visible not only at the level of syntax but also at the lexical level. Nominalization is as old as legal discourse itself and represents its essential component. Frequent nouns found in the corpus include performance, maintenance, permission, negligence, familiarization, instruction, watchkeeping, possession, collision, failure and navigation.

(46) The primary duties of OOW will involve watchkeeping, navigation and GMDSS radio watchkeeping.

(47) OOW must be in possession of STCW 95 certificate for ooW under the STCW Code.

Some of these are used as adjectives and have long been used in compounds such as watchkeeping officer, familirization check list/manual, maintenance record, collision avoidance or navigation bridge. It can be said that their use is more attributed to language economy, which has also largely entered into the maritime discourse community, particularly in the language of damage forms and check lists (Dževerdanović 2008, 2009). Thus, the phrase utmost importance occurs in twenty examples. It is a frequent phrase applied by Masters when they want to draw attention to the most important navigation issues. It occurs in 20 out of 40 examples, proving that Standing Orders do represent a kind of stable and recurrent discourse.

(48) It is therefore of utmost importance that at the first sign of deteriorating weather, the main engine is put on immediate notice.

(49) It is of utmost importance to report any factors which would affect course and speed, such as tide, weather or current.

(50) Proper maintenance and supervision of engine room is of utmost importance.

Apart from the fossilized expressions such as utmost importance, another example found in the corpus is all the time, that is at all times. It goes with the verb comply with. The emphasis on board ship in terms of the ship's security is on constant alertness and vigilance on the part of the ship's crew. There is no doubt that captains inherit from their older colleagues the captains discourse practice together with navigational knowledge. What is more, the era of digitalization and extensive use of computers on board is also reflected in the wording of documents on board, 
i.e. a copy-paste routine has unfortunately become a shipboard practice, as well.

\subsection{Move 3 - Standardized Ending}

The final part of the Standing Order as a genre cycles back to the legislative tone of discourse pertaining to Move 1 - Conventional Introduction. The graphical organization is also specific and individual words or even whole sentences are typed in capital letters. The pragmatic effect of the ending of Standing Orders in these examples is to warn the reader (crew) about the importance of the previously read texts. Just like the initial instances of legislative discourse, the sentences are long and syntactically discontinued.

(a) A good officer, when faced with any unusual circumstance, will apply COMMON SENSE and the good practice of seamen to the situation and act accordingly. If you find yourself thinking about calling the Master, then the time has clearly come to do so.

(b) IN CASE OF DOUBTS OR TROUBLES, CALL SHIP SECURITY OFFICER OR MASTER IMMEDIATELY SO AS TO PREVENT WORSE SITUATIONS AND EMERGENCY.

(c) THE MOMENT THERE IS THE SLIGHTEST DOUBT THAT SOMETHING IS WRONG OR SOMETHING MAY GO WRONG, OR IF THERE IS DOUBT OR NEED FOR ADDITIONAL ASSISTANCE, CALL ME IMMEDIATELY BECAUSE AT LATER STAGE IT MAY BE TOO LATE!

Additionally, the richest part of language, lexis, is fully employed to achieve a rhetoric effect as in the example (a) "common sense and the good practice of seamen", implying that the seamen in case of any emergency or distress shall use their sound judgement and react in the best interest of both the ship and the crew. The rhetorical effect is also managed by the choice of grammar in the second example (b) "If you find yourself thinking about calling the Master, then the time has clearly come to do so" meaning that all suspicious situations should immediately be reported. The emphasis is that the Master, and not the officers should make the decision and that the Master asks for notification about such situations. Whereas the presence of the Master in the first and second example is less visible ( $a$ and $b$ ), the third example (c) represents the Master's direct address to the officers and the tone is instructive, with the dramatic effect intensified in the words "too late" ("call me immediately because at later stage it may be too late").

Other examples of Standing Order documents do not contain a legislative discourse ending but rather a form of administrative wording $(51,52)$. To be specific, knowing that the Standing Orders represent a kind of tacit agree- ment made between the Master and the officers and that the officers guarantee that they know the content of the Orders by signing them, is reflected in Move 3 in the majority of endings of more recent date. Thus, ten examples of the texts do not contain Move 3 at all, whereas the others finish in a style characteristic of contracts and administrative discourse. The presence of the Master is rather distant and neutral. This may be explained by the fact that Standing Orders of a newer date are a part of the ship's documentation within the safety management system. There are forms and boxes and not much space is left for narrative.

(51) A master shall provide copy of the Standing Orders to the Ship Operation office at least annually and at any time the orders are revised.

(52) All bridge officers must read and understand these Standing Orders. In acknowledgement, they must enter this fact in the logbook the first time these orders are read by them. For any clarification a master or $\mathrm{C} / \mathrm{O}$ is to be contacted.

\section{Conclusion}

The form of Standing Orders has not changed over the years and it represents a relatively stable genre that provides a kind of unique communication channel between Master and crew (Turner, 2006). Standing Orders belong to a group of conventional and formulaic genres which have a similar surface structure in terms of content and graphical layout. Seafarers think of it as a predictable genre or a "copy-paste" document with nothing new to offer. Given that discourse analysis utilizes these surface exponents to explore the deeper structure of the text, the knowledge of legally binding discourse set forward by Bhatia (1993) is used in the analysis of the macro and micro levels of the texts. After establishing three recognized moves in the Standing Orders, the analysis shifted to an explanation of linguistic facts from a maritime scenario. The main pragmatic setting in this paper is about the authority of the Ship's Masters, establishing ship's rules and the rules of officers' behavior on board ship.

In the analysed corpus of a recent date (from 2000 to 2014), the Ship Master's presence is much more direct and personalized when compared to orders of earlier date (1980-1999) which are characterized by archaic discourse and fossilized legal expressions where the Master is more an intermediary between the law or rules (of the company) and the crew. As a genre, Standing Orders reflect social changes in the seafaring profession and it seems that the rapport between Master and crew has become much more flexible, despite the fact that the hierarchy and organization on board remains unchanged. The very content of the Standing Orders is regulative and it has to be neatly expressed, using recognizable segments and recognizable phrases. Given that a seafarer who has embarked on board the ship of a new company is faced with new a new working environment and docu- 
ments, the new Standing Orders text must be clear and unambiguous.

Finally, pedagogic outcome of this paper is to offer a possible model for acquiring this type of genre, particularly for deck officers and masters involved in this disciplinespecific document.

\section{References}

[1] Beetham, E. (2000) Master's Standing Orders. In: The Nautical Institute on Command: The Practical Guide, London. The Nautical Institute.

[2] Bhatia, V. (1993) Analyzing genre: Language Use in Professional Setting. London: Longman.

[3] Dževerdanović, M. (2008) "Discourse of Maritime Forms (Check Lists)". World Maritime University Journal of Maritime Affairs, 7(2), 449-465.

[4] Dževerdanović, M. (2009) “Genre Features of Damage Reports". Pomorstvo: Scientific Journal of Maritime Research, Vol. 23(1), 299-315.
[5] Frow, J. (2006) Genre. London and New York: Taylor \& Francis Group.

[6] Gotti, M. (2008) Investigating Specialized Discourse. London: Peter Lang.

[7] Gunnarsson, B.L. (2009) Professional Discourse. London and New York: Continuum.

[8] International Maritime Organization (2011) International Convention on Standards of Training, Certification and Watchkeeping for Seafarers including 2010 Manila Amendments. London: International Maritime Organization.

[9] International Maritime Organization (2001) Standard Marine Communication Phrases. Resolution A. 918(22), 29 November 2001. London: International Maritime Organization.

[10] Swales, J. (1990) Genre Analysis. New York: Cambridge University Press.

[11] Turner, K. H. (2006) Commanding officer's standing orders a powerful and unique genre. Master thesis, United States: Naval Postgraduate School. Available at: http://calhoun.nps. edu/handle/10945/2726. 